\title{
Mining of Microbial Genomes for the Novel Sources of Nitrilases
}

\author{
Nikhil Sharma, ${ }^{1}$ Neerja Thakur, ${ }^{2}$ Tilak Raj, ${ }^{1}$ Savitri, ${ }^{2}$ and Tek Chand Bhalla ${ }^{2}$ \\ ${ }^{1}$ Sub-Distributed Information Centre, Himachal Pradesh University, Summer Hill, Shimla 171005, India \\ ${ }^{2}$ Department of Biotechnology, Himachal Pradesh University, Summer Hill, Shimla 171005, India \\ Correspondence should be addressed to Tek Chand Bhalla; bhallatc@rediffmail.com
}

Received 25 October 2016; Revised 14 February 2017; Accepted 7 March 2017; Published 12 April 2017

Academic Editor: Jiangke Yang

Copyright (C) 2017 Nikhil Sharma et al. This is an open access article distributed under the Creative Commons Attribution License, which permits unrestricted use, distribution, and reproduction in any medium, provided the original work is properly cited.

\begin{abstract}
Next-generation DNA sequencing (NGS) has made it feasible to sequence large number of microbial genomes and advancements in computational biology have opened enormous opportunities to mine genome sequence data for novel genes and enzymes or their sources. In the present communication in silico mining of microbial genomes has been carried out to find novel sources of nitrilases. The sequences selected were analyzed for homology and considered for designing motifs. The manually designed motifs based on amino acid sequences of nitrilases were used to screen 2000 microbial genomes (translated to proteomes). This resulted in identification of one hundred thirty-eight putative/hypothetical sequences which could potentially code for nitrilase activity. In vitro validation of nine predicted sources of nitrilases was done for nitrile/cyanide hydrolyzing activity. Out of nine predicted nitrilases, Gluconacetobacter diazotrophicus, Sphingopyxis alaskensis, Saccharomonospora viridis, and Shimwellia blattae were specific for aliphatic nitriles, whereas nitrilases from Geodermatophilus obscurus, Nocardiopsis dassonvillei, Runella slithyformis, and Streptomyces albus possessed activity for aromatic nitriles. Flavobacterium indicum was specific towards potassium cyanide $(\mathrm{KCN})$ which revealed the presence of nitrilase homolog, that is, cyanide dihydratase with no activity for either aliphatic, aromatic, or aryl nitriles. The present study reports the novel sources of nitrilases and cyanide dihydratase which were not reported hitherto by in silico or in vitro studies.
\end{abstract}

\section{Introduction}

Advancement in the DNA sequencing technologies has led to sequencing of large number of genomes and the enormous sequence data are available in the public domain. The fourthgeneration DNA sequencing has made it possible to sequence a bacterial genome within a few hours at a reasonably low cost [1-4]. As of today 5293 prokaryotic and 22 eukaryotic genomes have been completely sequenced and the sequence data are easily accessible in databases such as NCBI, GOLD, and IMG/ER. It is evident from previous studies that not all the gene/protein sequences in the databases are functionally characterized, which make these repositories a rich source for the discovery of novel genes and proteins $[5,6]$. Genome mining has emerged as an alternate approach to find novel sources of desired genes/proteins as the conventional screening methods which involve isolation of microbes and their screening for desired products are time consuming, tedious, and cost intensive $[7,8]$.

Microbial nitrilases are considered to be the most important enzymes in the nitrilase superfamily that find application in the synthesis of fine chemicals, production of some important acids, and drug intermediates and in green chemistry [9-13]. Besides their wide applications nitrilases are prone to certain limitations, for example, their inactivation or inhibition by the acidic product, extremes of $\mathrm{pH}$, temperature, and organic solvent $[14,15]$. These limitations are being addressed either by the isolation of microorganisms from the extreme habitat or by enrichment techniques for specific substrate using conventional microbiological procedures [6] prone to limitation as mentioned above. The present communication focuses on in silico screening of publicly available bacterial genomes for nitrilase genes and in vitro validation of the predicted novel sources of nitrilases. 


\section{Material and Methods}

2.1. Genome Screening Using Homology and Motif Based Approach. Primary screening of microbial genomes (data given as supplementary material in Supplementary Material available online at https://doi.org/10.1155/2017/7039245) was done using homology based approach. Tblastn and blastp were used to screen the sequenced genomes with query sequence to identify the presence and position of similar genes in the genome. Computationally predicted proteins from the bacterial genomes with keyword "nitrilase/cyanide dihydratase" were also downloaded using advanced search options in the IMG/ER database. Sequences with low (30\%) and high similarity $(80 \%)$ were discarded. Nitrilase gene in contigs showing the presence of nitrilase homologs was downloaded from IMG/ER. GenMark S tool was used to predict the ORFs in each contig, and the output was downloaded selecting protein sequence as output option. Amino acid sequences less than 100 amino acids were considered to be as false positive (FP) and were discarded. Small amino acid sequence database was created which was further subjected to local blast, to confirm the presence of nitrilase homolog in the contigs of the individual genome.

On the other hand, protein based manually designed motifs (MDMs) were used to screen the bacterial genome to search for the presence of conserved motifs using MAST (Motif Alignment and Search Tool) at MEME (Multiple Em for Motif Elicitation) suite. The motifs used are already described in our previous communication [12]. Motifs identified in sequences less than hundred amino acids were rejected, considered to be false positive (FP). Sequences above 100 amino acids were taken to be as true positive (TP).

\subsection{Study of Physiochemical Properties and Phylogenetic} Analysis of Predicted Nitrilases. Physiochemical data of the in silico predicted nitrilases were generated from the ProtParam software using ExPASy server and compared to the values deduced from the previous nitrilase study [16]. Some important physiochemical properties such as number of amino acids, molecular weight (kda), isoelectric point (pI), computing $\mathrm{pI} / \mathrm{Mw}$ and the atomic compositions, values of instability index, aliphatic index, and grand average of hydropathicity (GRAVY) were calculated. A comparative chart was drawn between previously characterized and predicted nitrilases.

An output file of multiple aligned sequences using Clustal $\mathrm{W}$ for both previously characterized and predicted nitrilases was used to generate the Neighbor Joining (NJ) tree using MEGA 6 version. Phylogenetic tree was generated in order to predict the sequences as aliphatic or aromatic with previously characterized nitrilases.

2.3. Nitrilase Activity Assay. Culture of some of the bacteria predicted to have nitrilase gene (Shimwellia blattae, Runella slithyformis, Geodermatophilus obscurus, Nocardiopsis dassonvillei, Streptomyces albus, Flavobacterium indicum, Saccharomonospora viridis, Sphingopyxis alaskensis, and Gluconacetobacter diazotrophicus) was procured from Microbial Type Culture Collection (MTCC); Chandigarh Escherichia coli BL21 (DE3) from Invitrogen was used as negative control as this organism does not have nitrilase gene. These cultures were grown in the laboratory using different media (Table 1) for the production of nitrilase activity following the procedures described earlier [17-19]. Nitrilase activity was assayed in $1.0 \mathrm{~mL}$ reaction mixture containing nitrile as substrate $(1-10 \mathrm{mM})$ and $0.1 \mathrm{~mL}$ resting cells. After $30 \mathrm{~min}$ of incubation at $30^{\circ} \mathrm{C}$ the reaction was quenched with $0.1 \mathrm{M}$ $\mathrm{HCl}$ and the amount of ammonia released was estimated using nitrilase assay, that is, modified phenate-hypochlorite method described by Dennett and Blamey [20]. One unit of nitrilase activity was defined as the amount of enzyme required to release $1 \mu$ mole of ammonia per min under the assay conditions.

\section{Results}

3.1. Genome Screening Using Conserved Motifs and Homology Search. As many as 138 candidate sequences were identified using tblastn and blastp at IMG/ER on both gene and protein level. Identification of potentially coding nitrilase genes was done using homology based approach (blastp and tblastn) allowing the identification of nitrilase sequences. To identify newer sources of nitrilases, candidate sequences bearing unassigned functions (hypothetical, uncharacterized, or putative) were selected from the translated genomes (Table 2). The identified sequences shared $30-50 \%$ sequence identity to biochemically characterized Rhodococcus rhodochrous J1 nitrilase which was taken as query sequence. Catalytic residues were found to be conserved in all the predicted proteins. Nine predicted and translated sequences were further chosen for their in silico and in vitro validation based on the manually designed motifs (MDMs) (Tables 3 and 4) identified from previous study [12].

3.2. Physiochemical Parameters and Phylogenetic Analysis. In silico identified nitrilases were analyzed for their physiochemical properties using ProtParam, an online tool at the ExPASy proteomic server. The selected candidates values for various properties were found to be very much similar to those with earlier published data by Sharma and Bhalla [16] as mentioned in Table 5. Average values deduced for aliphatic and aromatic nitrilases from earlier characterized proteins were taken as standard for the comparison of a predicted set of nitrilase. The values of the same were found to be very much similar to those with earlier published data by Sharma and Bhalla [16] as mentioned in Table 5. The total number of amino acids ranged from 260 amino acids (Nocardiopsis dassonvillei) to 342 amino acids (Shimwellia blattae) with different molecular weight. Isoelectric point ranged between 4.8 and 5.8 which is found to be closer to the consensus value, that is, the average data value from previously characterized aliphatic or aromatic nitrilases.

Neighbor Joining (NJ) tree using MEGA 6 shows the phylogenetic analysis with in silico predicted sequences from completely sequenced microbial genomes with that of previously characterized nitrilase sequences. They were distinguished either as aliphatic or aromatic according to their position in the phylogenetic tree (Figure 1). 
TABLE 1: Composition of various media used to cultivate procured strains for nitrilase production.

\begin{tabular}{|c|c|c|c|c|}
\hline Name of the organism & MTCC number & Composition $\left(\mathrm{gL}^{-1}\right)$ & $\mathrm{pH}$ & Growth temperature \\
\hline $\begin{array}{l}\text { Shimwellia blattae } \\
\text { ATCC } 29907\end{array}$ & 4155 & $\begin{array}{l}\text { Beef extract: } 1.0 \mathrm{~g} \\
\text { Yeast extract: } 2.0 \mathrm{~g} \\
\text { Peptone: } 5.0 \mathrm{~g} \\
\mathrm{NaCl}: 5.0 \mathrm{~g} \\
\text { Agar: } 15.0 \mathrm{~g}\end{array}$ & $7.0-7.5$ & $37^{\circ} \mathrm{C}$ \\
\hline $\begin{array}{l}\text { Runella slithyformis } \\
\text { ATCC } 29530\end{array}$ & 9504 & $\begin{array}{l}\text { Glucose: } 1.0 \mathrm{~g} \\
\text { Peptone: } 1.0 \mathrm{~g} \\
\text { Yeast extract: } 1.0 \mathrm{~g} \\
\text { Agar: } 15.0 \mathrm{~g} \\
\text { Glucose: } 4.0 \mathrm{~g}\end{array}$ & $7.0-7.5$ & $26^{\circ} \mathrm{C}$ \\
\hline $\begin{array}{l}\text { Geodermatophilus obscurus } \\
\text { DSM } 43160\end{array}$ & 4040 & $\begin{array}{l}\text { Yeast extract: } 4.0 \mathrm{~g} \\
\text { Malt extract: } 10.0 \mathrm{~g} \\
\mathrm{CaCO}_{3}: 2.0 \mathrm{~g} \\
\text { Agar: } 12.0 \mathrm{~g}\end{array}$ & $7.2-7.5$ & $28^{\circ} \mathrm{C}$ \\
\hline $\begin{array}{l}\text { Nocardiopsis dassonvillei } \\
\text { DSM } 43111\end{array}$ & 1411 & $\begin{array}{l}\text { Yeast extract: } 4.0 \mathrm{~g} \\
\text { Malt extract: } 1.0 \\
\text { Glucose: } 4.0 \mathrm{~g} \\
\text { Agar: } 20.0 \mathrm{~g}\end{array}$ & $7.2-7.4$ & $28^{\circ} \mathrm{C}$ \\
\hline $\begin{array}{l}\text { Streptomyces albus } \\
\text { J1074 }\end{array}$ & 1138 & $\begin{array}{l}\text { Yeast extract: } 4.0 \mathrm{~g} \\
\text { Malt extract: } 1.0 \mathrm{~g} \\
\text { Glucose: } 4.0 \mathrm{~g} \\
\text { Agar: } 20.0 \mathrm{~g}\end{array}$ & $7.2-7.4$ & $25^{\circ} \mathrm{C}$ \\
\hline $\begin{array}{l}\text { Flavobacterium indicum } \\
\text { DSM } 17447\end{array}$ & 6936 & $\begin{array}{l}\text { Tryptic soy broth with agar } \\
\text { (TSBA-100) }\end{array}$ & $7.3-7.5$ & $30^{\circ} \mathrm{C}$ \\
\hline $\begin{array}{l}\text { Saccharomonospora viridis } \\
\text { ATCC } 15386\end{array}$ & 320 & $\begin{array}{l}\text { Yeast extract: } 4.0 \mathrm{~g} \\
\text { Malt extract: } 1.0 \mathrm{~g} \\
\text { Glucose: } 4.0 \mathrm{~g} \\
\text { Agar: } 20.0 \mathrm{~g}\end{array}$ & $7.2-7.4$ & $45^{\circ} \mathrm{C}$ \\
\hline $\begin{array}{l}\text { Sphingopyxis alaskensis } \\
\text { DSM } 13593\end{array}$ & 7504 & $\begin{array}{l}\text { Beef extract: } 1.0 \mathrm{~g} \\
\text { Yeast extract: } 2.0 \mathrm{~g} \\
\text { Peptone: } 5.0 \mathrm{~g} \\
\mathrm{NaCl}: 5.0 \mathrm{~g} \\
\text { Agar: } 15.0 \mathrm{~g}\end{array}$ & $7.0-7.5$ & $30^{\circ} \mathrm{C}$ \\
\hline $\begin{array}{l}\text { Gluconacetobacter } \\
\text { diazotrophicus } \\
\text { ATCC } 49037\end{array}$ & 1224 & $\begin{array}{l}\text { Yeast extract: } 5.0 \mathrm{~g} \\
\text { Peptone: } 3.0 \mathrm{~g} \\
\text { Mannitol: } 25.0 \mathrm{~g} \\
\text { Agar: } 15.0 \mathrm{~g}\end{array}$ & $7.0-7.3$ & $28^{\circ} \mathrm{C}$ \\
\hline $\begin{array}{l}\text { Escherichia coli } \\
\text { BL21 (DE3) }\end{array}$ & - & $\begin{array}{l}\text { Yeast extract: } 5.0 \mathrm{~g} \\
\mathrm{NaCl}: 10.0 \mathrm{~g} \\
\text { Casein enzymatic } \\
\text { hydrolysate: } 10.0 \mathrm{~g}\end{array}$ & $7.0-7.5$ & $37^{\circ} \mathrm{C}$ \\
\hline
\end{tabular}

${ }^{*}$ Negative control.

3.3. In Vitro Validation of Some In Silico Predicted Nitrilases. To validate for nitrile transforming activity of nine predicted novel sources of nitrilases, these were tested against common aliphatic, aromatic, and aryl nitriles and potassium cyanide (KCN). Gluconacetobacter diazotrophicus, Sphingopyxis alaskensis, Saccharomonospora viridis, and Shimwellia blattae were found to be more specific for aliphatic nitriles. On the other hand, Geodermatophilus obscurus, Nocardiopsis dassonvillei, Runella slithyformis, and Streptomyces albus exhibited nitrilase activity for aromatic nitriles. Flavobacterium indicum was the only organism which showed no activity for either aliphatic, aromatic, or aryl nitriles but was specific towards the degradation of the potassium cyanide
(KCN) (Table 6). On the other hand, negative control, that is, Escherichia coli BL21 (DE3), showed no activity for any of the nitriles/substrates tested.

\section{Discussion}

Annotation of sequenced genomes to identify new genes has become integral part of the research in bioinformatics [21-24]. The present investigation has revealed some novel sources of nitrilases. Homology and conserved motif approach screened microbial genomes and proteins predicted as nitrilase or cyanide dihydratase or carbon-nitrogen hydrolase in 138 prokaryotic bacterial genomes. Manually 
TABLE 2: Prediction of ORFs length in the individual scaffold for prediction of coding sequence for nitrilase using IMG/ER.

\begin{tabular}{|c|c|c|c|c|}
\hline Name of organism & $\begin{array}{l}\text { Scaffold or genome } \\
\text { length (bp) with } \\
\text { accession number }\end{array}$ & $\begin{array}{l}\text { Total number of } \\
\text { ORF's predicted in } \\
\text { scaffold of } \\
\text { complete genome }\end{array}$ & $\begin{array}{l}\text { Predicted coding } \\
\text { region for nitrilase }\end{array}$ & $\begin{array}{l}\text { Number of } \\
\text { base-pairs }\end{array}$ \\
\hline $\begin{array}{l}\text { Acaryochloris marina } \\
\text { MBIC11017 }\end{array}$ & $\begin{array}{l}\text { NC_009925 } \\
\text { (6503724 bp) }\end{array}$ & 152 & 200001-200999 & 999 \\
\hline $\begin{array}{l}\text { Acetobacter pasteurianus } \\
\text { IFO 3283-32 }\end{array}$ & $\begin{array}{l}\text { AP011157 } \\
\text { (191443 bp) }\end{array}$ & 120 & $174107-173133$ & 974 \\
\hline $\begin{array}{l}\text { Achromobacter } \\
\text { xylosoxidans } \\
\text { A8 } \\
\end{array}$ & $\begin{array}{l}\text { NC_014640 } \\
(7013095 \mathrm{bp})\end{array}$ & 406 & $200001-200960$ & 960 \\
\hline $\begin{array}{l}\text { Acidovorax avenae avenae } \\
\text { ATCC } 19860\end{array}$ & $\begin{array}{l}\text { NC_015138 } \\
(5482170 \text { bp })\end{array}$ & 188 & 201035-200001 & 1035 \\
\hline $\begin{array}{l}\text { Acidothermus cellulolyticus } \\
11 \mathrm{~B}\end{array}$ & $\begin{array}{l}\text { NC_008578 } \\
(2443540 \text { bp })\end{array}$ & 403 & 200001-201131 & 1131 \\
\hline $\begin{array}{l}\text { Acidaminococcus } \\
\text { fermentans } \\
\text { VR4 } \\
\end{array}$ & $\begin{array}{l}\text { NC_013740 } \\
(2329769 \mathrm{bp})\end{array}$ & 293 & 200924-200001 & 924 \\
\hline $\begin{array}{l}\text { Alcanivorax dieselolei } \\
\text { B5 }\end{array}$ & $\begin{array}{c}\text { CP003466 } \\
\text { (4928223 bp) }\end{array}$ & 343 & 200001-200981 & 981 \\
\hline $\begin{array}{l}\text { Arthrobacter aurescens } \\
\text { TC1 }\end{array}$ & $\begin{array}{l}\text { NC_008711 } \\
(4597686 \mathrm{bp})\end{array}$ & 385 & 200001-200930 & 930 \\
\hline $\begin{array}{l}\text { Azorhizobium caulinodans } \\
\text { ORS } 571\end{array}$ & $\begin{array}{l}\text { NC_009937 } \\
(5369772 \text { bp) }\end{array}$ & 262 & $89665-88580$ & 1083 \\
\hline $\begin{array}{l}\text { Azospirillum sp. } \\
\text { B510 }\end{array}$ & $\begin{array}{l}\text { NC_013854 } \\
(3311395 \text { bp) }\end{array}$ & 402 & $200001-200921$ & 921 \\
\hline $\begin{array}{l}\text { Bacillus pumilus } \\
\text { SAFR-032 }\end{array}$ & $\begin{array}{l}\text { NC_009848 } \\
\text { (3704465 bp) }\end{array}$ & 73 & $201026-200001$ & 1026 \\
\hline $\begin{array}{l}\text { Bradyrhizobium japonicum } \\
\text { USDA } 110\end{array}$ & $\begin{array}{l}\text { NC_004463 } \\
(9105828 \text { bp) }\end{array}$ & 387 & 200001-200966 & 966 \\
\hline $\begin{array}{l}\text { Bradyrhizobium sp. } \\
\text { BTAil }\end{array}$ & $\begin{array}{l}\text { NC_009485 } \\
(8264687 \mathrm{bp})\end{array}$ & 392 & 201146-200001 & 1146 \\
\hline $\begin{array}{l}\text { Bradyrhizobium sp. } \\
\text { ORS278 }\end{array}$ & $\begin{array}{l}\text { NC_009445 } \\
(7456587 \mathrm{bp})\end{array}$ & 395 & 201041-200001 & 1041 \\
\hline $\begin{array}{l}\text { Brevibacillus brevis } \\
\text { NBRC } 100599 \\
\end{array}$ & $\begin{array}{c}\text { NC_012491 } \\
(6296436 \text { bp) }\end{array}$ & 182 & 200001-200960 & 960 \\
\hline $\begin{array}{l}\text { Flavobacterium indicum } \\
\text { GPTSA100-9 }\end{array}$ & $\begin{array}{l}\text { HE774682 } \\
\text { (2993089 bp) }\end{array}$ & 317 & 200001-200981 & 981 \\
\hline $\begin{array}{l}\text { Saccharomonospora viridis } \\
\text { P101 }\end{array}$ & $\begin{array}{c}\text { NC_013159 } \\
(4308349 \mathrm{bp})\end{array}$ & 315 & 200001-200996 & 996 \\
\hline $\begin{array}{l}\text { Sphingopyxis alaskensis } \\
\text { DSM13593 }\end{array}$ & $\begin{array}{l}\text { NC_008048 } \\
(3345170 \text { bp })\end{array}$ & 387 & 200001-201017 & 1017 \\
\hline $\begin{array}{l}\text { Burkholderia cenocepacia } \\
\mathrm{J} 2315\end{array}$ & $\begin{array}{l}\text { NC_011000 } \\
(3870082 \text { bp })\end{array}$ & 393 & 199944-201050 & 1050 \\
\hline $\begin{array}{l}\text { Burkholderia glumae } \\
\text { BGR1 }\end{array}$ & $\begin{array}{l}\text { NC_012720 } \\
(141067 \mathrm{bp}) \\
\end{array}$ & 154 & $47491-48477$ & 1017 \\
\hline $\begin{array}{l}\text { Burkholderia gladioli } \\
\text { BSR3 }\end{array}$ & $\begin{array}{l}\text { NC_015376 } \\
(3700833 \mathrm{bp})\end{array}$ & 338 & 200001-201014 & 1014 \\
\hline Burkholderia phymatum & $\begin{array}{l}\text { NC_010623 } \\
(2697374 \mathrm{bp})\end{array}$ & 375 & $199971-201023$ & 1023 \\
\hline Burkholderia phytofirmans & $\begin{array}{c}\text { NC_010681 } \\
(4467537 \mathrm{bp})\end{array}$ & 357 & $200001-201035$ & 1035 \\
\hline $\begin{array}{l}\text { Burkholderia sp. } \\
\text { CCGE1002 }\end{array}$ & $\begin{array}{l}\text { NC_014119 } \\
(1282816 \mathrm{bp})\end{array}$ & 280 & $72013-73041$ & 1020 \\
\hline $\begin{array}{l}\text { Burkholderia sp. } \\
\text { CCGE1003 }\end{array}$ & $\begin{array}{l}\text { NC_014540 } \\
(2966498 \mathrm{bp})\end{array}$ & 344 & 200019-201041 & 1022 \\
\hline
\end{tabular}


TABLE 2: Continued.

\begin{tabular}{|c|c|c|c|c|}
\hline Name of organism & $\begin{array}{l}\text { Scaffold or genome } \\
\text { length (bp) with } \\
\text { accession number }\end{array}$ & $\begin{array}{l}\text { Total number of } \\
\text { ORF's predicted in } \\
\text { scaffold of } \\
\text { complete genome }\end{array}$ & $\begin{array}{l}\text { Predicted coding } \\
\text { region for nitrilase }\end{array}$ & $\begin{array}{l}\text { Number of } \\
\text { base-pairs }\end{array}$ \\
\hline $\begin{array}{l}\text { Burkholderia vietnamiensis } \\
\text { G4 }\end{array}$ & $\begin{array}{l}\text { NC_009254 } \\
(1241007 \mathrm{bp})\end{array}$ & 436 & 199986-201023 & 1037 \\
\hline $\begin{array}{l}\text { Burkholderia xenovorans } \\
\text { LB400 }\end{array}$ & $\begin{array}{l}\text { NC_007951 } \\
(4895836 \text { bp) }\end{array}$ & 396 & 200001-200996 & 996 \\
\hline Caulobacter sp. K31 & $\begin{array}{l}\text { NC_010335 } \\
\text { (233649 bp) }\end{array}$ & 219 & 180936-181871 & 935 \\
\hline $\begin{array}{l}\text { Chlorobium } \\
\text { phaeobacteroides } \\
\text { BS1 }\end{array}$ & $\begin{array}{l}\text { NC_010831 } \\
(2736403 \text { bp) }\end{array}$ & 382 & 200001-200936 & 936 \\
\hline Clostridium difficile 630 & $\begin{array}{l}\text { NC_009089 } \\
\text { (4290252 bp) }\end{array}$ & 364 & 200001-200927 & 927 \\
\hline $\begin{array}{l}\text { Clostridium difficile } \\
\text { CD196 }\end{array}$ & $\begin{array}{l}\text { NC_013315 } \\
(4110554 \mathrm{bp})\end{array}$ & 308 & 200001-200927 & 927 \\
\hline $\begin{array}{l}\text { Clostridium difficile } \\
\text { R20291 }\end{array}$ & $\begin{array}{l}\text { NC_013316 } \\
(4191339 \text { bp) }\end{array}$ & 329 & 200001-200927 & 927 \\
\hline $\begin{array}{l}\text { Clostridium kluyveri } \\
\text { NBRC } 12016\end{array}$ & $\begin{array}{c}\text { NC_011837 } \\
(3896121 \text { bp) }\end{array}$ & 442 & 200001-200930 & 957 \\
\hline $\begin{array}{l}\text { Clostridium kluyveri } \\
\text { ATCC } 8527\end{array}$ & $\begin{array}{l}\text { NC_009706 } \\
(3964618 \mathrm{bp})\end{array}$ & 491 & 200001-200930 & 930 \\
\hline $\begin{array}{l}\text { Conexibacter woesei } \\
\text { DSM } 14684\end{array}$ & $\begin{array}{l}\text { NC_013739 } \\
\text { (6359369 bp) }\end{array}$ & 388 & 200001-200942 & 942 \\
\hline $\begin{array}{l}\text { Cupriavidus necator } \\
\text { ATCC } 17699\end{array}$ & $\begin{array}{l}\text { NC_008313 } \\
(4052032 \text { bp) }\end{array}$ & 318 & 200001-201017 & 1017 \\
\hline $\begin{array}{l}\text { Cupriavidus necator } \\
\text { ATCC } 43291\end{array}$ & $\begin{array}{c}\text { NC_015726 } \\
\text { (3872936 bp) }\end{array}$ & 318 & 200001-201017 & 1017 \\
\hline $\begin{array}{l}\text { Cyanobium gracile } \\
\text { ATCC } 27147\end{array}$ & $\begin{array}{c}\text { Cyagr_Contig81 } \\
(3342364 \text { bp })\end{array}$ & 405 & 200001-200999 & 999 \\
\hline $\begin{array}{l}\text { Deinococcus deserti } \\
\text { (strain VCD115) }\end{array}$ & $\begin{array}{l}\text { NC_012529 } \\
\text { (314317 bp) }\end{array}$ & 269 & 200001-200951 & 951 \\
\hline $\begin{array}{l}\text { Deinococcus peraridilitoris } \\
\text { DSM } 19664\end{array}$ & $\begin{array}{l}\text { Deipe_Contig72.1 } \\
\text { (3881839 bp) }\end{array}$ & 412 & 200001-200951 & 951 \\
\hline $\begin{array}{l}\text { Desulfomonile tiedjei } \\
\text { ATCC } 49306\end{array}$ & $\begin{array}{l}\text { Desti_Contig107.1 } \\
\quad(6500104 \mathrm{bp})\end{array}$ & 379 & 200001-201029 & 1029 \\
\hline Dickeya zeae Ech1591 & $\begin{array}{l}\text { NC_012912 } \\
(4813854 \text { bp) }\end{array}$ & 194 & 200001-200927 & 927 \\
\hline Erwinia billingiae Eb661 & $\begin{array}{l}\text { NC_014305 } \\
(169778 \text { bp) }\end{array}$ & 194 & $87964-88965$ & 1001 \\
\hline $\begin{array}{l}\text { Erythrobacter litoralis } \\
\text { HTCC } 2594\end{array}$ & $\begin{array}{l}\text { NC_007722 } \\
\text { (3052398 bp) }\end{array}$ & 411 & 200001-200969 & 969 \\
\hline $\begin{array}{l}\text { Flavobacterium indicum } \\
\text { DSM } 17447\end{array}$ & $\begin{array}{l}\text { HE774682 } \\
\text { (2993089 bp) }\end{array}$ & 317 & 200001-200981 & 981 \\
\hline $\begin{array}{l}\text { Frateuria aurantia } \\
\text { ATCC } 33424\end{array}$ & $\begin{array}{c}\text { Fraau_Contig } 24.1 \\
(3603458 \mathrm{bp})\end{array}$ & 366 & 200001-200924 & 924 \\
\hline $\begin{array}{l}\text { Geobacillus sp. } \\
\text { Y4.1MC1 }\end{array}$ & $\begin{array}{l}\text { NC_014650 } \\
(3840330 \text { bp) }\end{array}$ & 434 & 200001-200966 & 966 \\
\hline $\begin{array}{l}\text { Geobacillus } \\
\text { thermoglucosidasius } \\
\text { C56-YS93 }\end{array}$ & $\begin{array}{l}\text { NC_015660 } \\
\text { (3893306 bp) }\end{array}$ & 446 & 200001-200966 & 966 \\
\hline $\begin{array}{l}\text { Geodermatophilus obscurus } \\
\text { DSM } 43160\end{array}$ & $\begin{array}{l}\text { NC_013757 } \\
\text { (5322497 bp) }\end{array}$ & 244 & $54102-54884$ & 783 \\
\hline
\end{tabular}


TABLe 2: Continued.

\begin{tabular}{|c|c|c|c|c|}
\hline Name of organism & $\begin{array}{l}\text { Scaffold or genome } \\
\text { length (bp) with } \\
\text { accession number }\end{array}$ & $\begin{array}{l}\text { Total number of } \\
\text { ORF's predicted in } \\
\text { scaffold of } \\
\text { complete genome }\end{array}$ & $\begin{array}{l}\text { Predicted coding } \\
\text { region for nitrilase }\end{array}$ & $\begin{array}{l}\text { Number of } \\
\text { base-pairs }\end{array}$ \\
\hline $\begin{array}{l}\text { Gluconacetobacter } \\
\text { diazotrophicus } \\
\text { ATCC } 49037\end{array}$ & $\begin{array}{l}\text { NC_010125 } \\
(3944163 \mathrm{bp})\end{array}$ & 333 & 200001-200960 & 960 \\
\hline $\begin{array}{l}\text { Haliangium ochraceum } \\
\text { DSM } 14365\end{array}$ & $\begin{array}{c}\mathrm{CP} 002175 \\
(2309262 \mathrm{bp})\end{array}$ & 377 & 200001-200957 & 957 \\
\hline $\begin{array}{l}\text { Halanaerobium praevalens } \\
\text { ATCC } 33744\end{array}$ & $\begin{array}{l}\text { NC_013440 } \\
(9446314 \mathrm{bp})\end{array}$ & 262 & 200001-200999 & 999 \\
\hline $\begin{array}{l}\text { Hyphomicrobium sp. } \\
\text { MC1 }\end{array}$ & $\begin{array}{c}\text { NC_015717 } \\
(4757528 \mathrm{bp})\end{array}$ & 392 & 200001-200984 & 984 \\
\hline $\begin{array}{l}\text { Janthinobacterium sp. } \\
\text { Marseille }\end{array}$ & $\begin{array}{l}\text { NC_009659 } \\
(4110251 \mathrm{bp}) \\
\end{array}$ & 398 & 200001-201068 & 1068 \\
\hline $\begin{array}{l}\text { Jannaschia sp. } \\
\text { CCS1 }\end{array}$ & $\begin{array}{l}\text { NC_007802 } \\
(4317977 \mathrm{bp})\end{array}$ & 382 & $200001-201026$ & 1026 \\
\hline $\begin{array}{l}\text { Maricaulis maris } \\
\text { MCS10 }\end{array}$ & $\begin{array}{l}\text { NC_008347 } \\
(3368780 \mathrm{bp})\end{array}$ & 392 & 200001-200933 & 933 \\
\hline $\begin{array}{l}\text { Methylobacterium } \\
\text { extorquens CM4 }\end{array}$ & $\begin{array}{l}\text { NC_011758 } \\
(380207 \text { bp) }\end{array}$ & 211 & $7191-8267$ & 1077 \\
\hline $\begin{array}{l}\text { Methylobacterium } \\
\text { extorquens } \\
\text { ATCC } 14718\end{array}$ & $\begin{array}{l}\text { NC_012811 } \\
(1261460 \mathrm{bp})\end{array}$ & 436 & 200001-201077 & 1077 \\
\hline $\begin{array}{l}\text { Methylobacterium } \\
\text { extorquens DM4 }\end{array}$ & $\begin{array}{l}\text { NC_012988 } \\
(5943768 \mathrm{bp})\end{array}$ & 378 & 200001-200918 & 918 \\
\hline $\begin{array}{l}\text { Methylobacterium } \\
\text { extorquens PA1 }\end{array}$ & $\begin{array}{l}\text { NC_010172 } \\
(5471154 \text { bp) }\end{array}$ & 354 & 200001-201110 & 1110 \\
\hline $\begin{array}{l}\text { Methylomonas methanica } \\
\text { MC09 }\end{array}$ & $\begin{array}{c}\text { Contig38 } \\
(5051681 \mathrm{bp}) \\
\end{array}$ & 402 & 200001-200996 & 996 \\
\hline $\begin{array}{l}\text { Methylobacterium nodulans } \\
\text { ORS2060 }\end{array}$ & $\begin{array}{l}\text { NC_011892 } \\
(487734 \text { bp) }\end{array}$ & 425 & 200001-201116 & 1116 \\
\hline $\begin{array}{l}\text { Methylobacterium populi } \\
\text { ATCC BAA-705 }\end{array}$ & $\begin{array}{l}\text { NC_010725 } \\
(5800441 \mathrm{bp})\end{array}$ & 193 & $61617-62693$ & 1077 \\
\hline $\begin{array}{l}\text { Methylibium petroleiphilum } \\
\text { PM1 }\end{array}$ & $\begin{array}{l}\text { NC_008825 } \\
(4044195 \mathrm{bp})\end{array}$ & 364 & 200001-201074 & 1074 \\
\hline $\begin{array}{l}\text { Methylobacterium } \\
\text { radiotolerans } \\
\text { ATCC } 27329 \\
\end{array}$ & $\begin{array}{l}\text { NC_010505 } \\
(6077833 \mathrm{bp})\end{array}$ & 377 & 200001-201077 & 1077 \\
\hline $\begin{array}{l}\text { Methylocella silvestris } \\
\text { BL2 }\end{array}$ & $\begin{array}{l}\text { NC_011666 } \\
(4305430 \text { bp })\end{array}$ & 439 & 199971-201029 & 1029 \\
\hline $\begin{array}{l}\text { Mycobacterium } \\
\text { intracellulare } \\
\text { ATCC } 13950 \\
\end{array}$ & $\begin{array}{c}\text { CP003322 } \\
(5402402 \mathrm{bp})\end{array}$ & 383 & 199938-200897 & 897 \\
\hline $\begin{array}{l}\text { Mycobacterium liflandii } \\
128 \mathrm{FXT}\end{array}$ & $\begin{array}{c}\text { CP003899 } \\
(6208955 \mathrm{bp})\end{array}$ & 405 & 200001-201059 & 1059 \\
\hline $\begin{array}{l}\text { Mycobacterium rhodesiae } \\
\text { NBB3 }\end{array}$ & $\begin{array}{c}\text { MycrhN_Contig54.1 } \\
\text { (6415739 bp) }\end{array}$ & 267 & 200001-200957 & 957 \\
\hline $\begin{array}{l}\text { Mycobacterium smegmatis } \\
\text { ATCC } 700084\end{array}$ & $\begin{array}{c}\text { CP001663 } \\
(6988208 \mathrm{bp})\end{array}$ & 377 & 200001-200978 & 978 \\
\hline $\begin{array}{l}\text { Natranaerobius } \\
\text { thermophilus } \\
\text { ATCC BAA-1301 }\end{array}$ & $\begin{array}{c}\text { NC_010718 } \\
(3165557 \text { bp) }\end{array}$ & 387 & 200001-200930 & 930 \\
\hline
\end{tabular}


TABLE 2: Continued.

\begin{tabular}{|c|c|c|c|c|}
\hline Name of organism & $\begin{array}{l}\text { Scaffold or genome } \\
\text { length (bp) with } \\
\text { accession number }\end{array}$ & $\begin{array}{l}\text { Total number of } \\
\text { ORF's predicted in } \\
\text { scaffold of } \\
\text { complete genome }\end{array}$ & $\begin{array}{l}\text { Predicted coding } \\
\text { region for nitrilase }\end{array}$ & $\begin{array}{l}\text { Number of } \\
\text { base-pairs }\end{array}$ \\
\hline $\begin{array}{l}\text { Nocardia farcinica } \\
\text { IFM } 10152\end{array}$ & $\begin{array}{l}\text { NC_006361 } \\
(6021225 \text { bp) }\end{array}$ & 390 & 198993-199811 & 818 \\
\hline $\begin{array}{l}\text { Nocardiopsis dassonvillei } \\
\text { DSM } 43111\end{array}$ & $\begin{array}{l}\text { NC_014211 } \\
(775354 \text { bp) }\end{array}$ & 353 & 201134-200001 & 843 \\
\hline $\begin{array}{l}\text { Oligotropha } \\
\text { carboxidovorans } \\
\text { ATCC } 49405 \\
\end{array}$ & $\begin{array}{c}\text { CP002826 } \\
(3595748 \mathrm{bp})\end{array}$ & 372 & 200001-201065 & 1065 \\
\hline Pantoea sp. At-9b & $\begin{array}{l}\text { NC_014839 } \\
(394054 \text { bp }) \\
\end{array}$ & 349 & $114577-115581$ & 1005 \\
\hline $\begin{array}{l}\text { Peptoniphilus duerdenii } \\
\text { ATCC BAA-1640 }\end{array}$ & $\begin{array}{c}\text { NZ_AEEH01000050 } \\
(96694 \mathrm{bp})\end{array}$ & 80 & $52942-53863$ & 921 \\
\hline $\begin{array}{l}\text { Photorhabdus asymbiotica } \\
\text { ATCC } 43949\end{array}$ & $\begin{array}{c}\text { NC_012962 } \\
(5064808 \text { bp })\end{array}$ & 338 & $200001-201050$ & 1050 \\
\hline $\begin{array}{l}\text { Pirellula staleyi } \\
\text { ATCC } 27377 \\
\end{array}$ & $\begin{array}{l}\text { NC_013720 } \\
(6196199 \text { bp) }\end{array}$ & 338 & 200001-200909 & 909 \\
\hline $\begin{array}{l}\text { Polaromonas } \\
\text { naphthalenivorans } \\
\text { CJ2 } \\
\end{array}$ & $\begin{array}{l}\text { NC_008781 } \\
(4410291 \mathrm{bp})\end{array}$ & 389 & 200001-201041 & 1062 \\
\hline Polaromonas sp. JS666 & $\begin{array}{c}\text { NC_007948 } \\
(5200264 \mathrm{bp}) \\
\end{array}$ & 398 & 200001-200942 & 942 \\
\hline $\begin{array}{l}\text { Pseudomonas syringae pv. } \\
\text { lachrymans } \\
\text { M302278PT }\end{array}$ & $\begin{array}{l}\text { Lac106_115287.20 } \\
\text { (115287 bp) }\end{array}$ & 107 & $47704-48747$ & 1043 \\
\hline $\begin{array}{l}\text { Pseudoalteromonas } \\
\text { atlantica } \\
\text { ATCC BAA-1087 } \\
\end{array}$ & $\begin{array}{l}\text { NC_008228 } \\
(5187005 \mathrm{bp})\end{array}$ & 397 & 200001-200921 & 921 \\
\hline $\begin{array}{l}\text { Pseudomonas aeruginosa } \\
\text { P7-L633/96 }\end{array}$ & $\begin{array}{c}\text { Ga0060317_132 } \\
(369634 \mathrm{bp})\end{array}$ & 270 & 91986-92801 & 816 \\
\hline $\begin{array}{l}\text { Pseudomonas } \\
\text { brassicacearum } \\
\text { NFM421 } \\
\end{array}$ & $\begin{array}{l}\text { NC_015379 } \\
(6843248 \text { bp })\end{array}$ & 377 & 200001-201026 & 1026 \\
\hline Pseudomonas sp. TJI-51 & $\begin{array}{l}\text { AEWE01000051 } \\
\text { (6502 bp) }\end{array}$ & 05 & $1482-2498$ & 1017 \\
\hline $\begin{array}{l}\text { Pseudomonas fluorescens } \\
\text { Pf-5 }\end{array}$ & $\begin{array}{l}\text { NC_007492 } \\
(6438405 \text { bp) }\end{array}$ & 349 & 200001-200924 & 924 \\
\hline $\begin{array}{l}\text { Pseudomonas fluorescens } \\
\text { SBW25 }\end{array}$ & $\begin{array}{l}\text { NC_012660 } \\
(6722539 \mathrm{bp})\end{array}$ & 376 & 200043-200930 & 888 \\
\hline $\begin{array}{l}\text { Pseudomonas mendocina } \\
\text { NK-01 }\end{array}$ & $\begin{array}{l}\text { NC_015410 } \\
(5434353 \mathrm{bp})\end{array}$ & 376 & 200001-200883 & 883 \\
\hline $\begin{array}{l}\text { Pseudomonas syringae } \\
\text { pv. tomato DC } 3000\end{array}$ & $\begin{array}{c}\text { PSPTOimg_DC3000 } \\
(6397126 \mathrm{bp})\end{array}$ & 377 & 200001-201011 & 1011 \\
\hline $\begin{array}{l}\text { Pseudomonas syringae } \\
\text { pv. syringae } \mathrm{B} 728 \mathrm{a}\end{array}$ & $\begin{array}{l}\text { NC_007005 } \\
(6093698 \text { bp })\end{array}$ & 196 & $8233-9231$ & 999 \\
\hline $\begin{array}{l}\text { Pseudoxanthomonas } \\
\text { suwonensis11-1 }\end{array}$ & $\begin{array}{l}\text { NC_014924 } \\
(3419049 \text { bp) }\end{array}$ & 362 & 200001-200885 & 885 \\
\hline $\begin{array}{l}\text { Pseudonocardia } \\
\text { dioxanivorans } \\
\text { ATCC } 55486 \\
\end{array}$ & $\begin{array}{c}\text { CP002593 } \\
\text { (7096571bp) }\end{array}$ & 386 & 200001-201008 & 1008 \\
\hline $\begin{array}{l}\text { Ralstonia solanacearum } \\
\text { GMI1000 }\end{array}$ & $\begin{array}{l}\text { NC_003295 } \\
(3716413 \mathrm{bp})\end{array}$ & 343 & 200001-201032 & 1032 \\
\hline $\begin{array}{l}\text { Rhizobium hainanense } \\
\text { CCBAU } 57015\end{array}$ & $\begin{array}{c}\text { Ga0061100_113 } \\
(148344 \mathrm{bp})\end{array}$ & 146 & $61240-62280$ & 1040 \\
\hline
\end{tabular}


TABLE 2: Continued.

\begin{tabular}{|c|c|c|c|c|}
\hline Name of organism & $\begin{array}{l}\text { Scaffold or genome } \\
\text { length (bp) with } \\
\text { accession number }\end{array}$ & $\begin{array}{l}\text { Total number of } \\
\text { ORF's predicted in } \\
\text { scaffold of } \\
\text { complete genome }\end{array}$ & $\begin{array}{l}\text { Predicted coding } \\
\text { region for nitrilase }\end{array}$ & $\begin{array}{l}\text { Number of } \\
\text { base-pairs }\end{array}$ \\
\hline $\begin{array}{l}\text { Rhizobium leguminosarum bv. } \\
\text { Viciae } 3841\end{array}$ & $\begin{array}{l}\text { NC_008380 } \\
(5057142 \text { bp })\end{array}$ & 397 & $200001-201047$ & 1047 \\
\hline $\begin{array}{l}\text { Rhizobium leguminosarum bv. } \\
\text { trifolii } \\
\text { WSM1325 }\end{array}$ & $\begin{array}{l}\text { NC_012850 } \\
(4767043 \mathrm{bp})\end{array}$ & 210 & $18450-19442$ & 993 \\
\hline $\begin{array}{l}\text { Rhodopseudomonaspalustris } \\
\text { TIE-1 }\end{array}$ & $\begin{array}{l}\text { NC_011004 } \\
(5744041 \mathrm{bp})\end{array}$ & 387 & 199980-201050 & 1070 \\
\hline $\begin{array}{l}\text { Rhodopseudomonas palustris } \\
\text { DX-1 }\end{array}$ & $\begin{array}{l}\text { NC_014834 } \\
(5404117 \text { bp) }\end{array}$ & 390 & 200001-200954 & 954 \\
\hline $\begin{array}{l}\text { Rubrobacter xylanophilus } \\
\text { DSM } 9941\end{array}$ & $\begin{array}{l}\text { NC_008148 } \\
(3225748 \mathrm{bp})\end{array}$ & 385 & 200001-201080 & 1080 \\
\hline $\begin{array}{l}\text { Ruegeria pomeroyi } \\
\text { ATCC } 700808\end{array}$ & $\begin{array}{c}\text { NC_006569 } \\
(491611 \mathrm{bp}) \\
\end{array}$ & 308 & 118859-119893 & 1035 \\
\hline $\begin{array}{l}\text { Runella slithyformis } \\
\text { ATCC } 29530\end{array}$ & $\begin{array}{c}\text { Unknown } \\
(6568739 \mathrm{bp})\end{array}$ & 362 & $200001-200933$ & 933 \\
\hline $\begin{array}{l}\text { Saccharothrix espanaensis } \\
\text { ATCC } 51144\end{array}$ & $\begin{array}{c}\text { HE804045 } \\
(9360653 \mathrm{bp})\end{array}$ & 347 & 200001-201020 & 1020 \\
\hline $\begin{array}{l}\text { Saccharomonospora viridis } \\
\text { ATCC } 15386\end{array}$ & $\begin{array}{c}\text { NC_013159 } \\
(4308349 \mathrm{bp}) \\
\end{array}$ & 315 & 200001-200996 & 996 \\
\hline $\begin{array}{l}\text { Shewanella halifaxensis } \\
\text { HAW-EB4 }\end{array}$ & $\begin{array}{c}\text { NC_010334 } \\
(5226917 \text { bp })\end{array}$ & 337 & 200001-200945 & 945 \\
\hline $\begin{array}{l}\text { Shewanella pealeana } \\
\text { ATCC } 700345\end{array}$ & $\begin{array}{l}\text { NC_009901 } \\
(5174581 \mathrm{bp}) \\
\end{array}$ & 333 & 200001-200945 & 945 \\
\hline $\begin{array}{l}\text { Shewanella sediminis } \\
\text { HAW-EB3 }\end{array}$ & $\begin{array}{l}\text { NC_009831 } \\
(5517674 \mathrm{bp}) \\
\end{array}$ & 337 & 200001-200954 & 954 \\
\hline $\begin{array}{l}\text { Shewanella violacea } \\
\text { JCM } 1017\end{array}$ & $\begin{array}{c}\text { NC_014012 } \\
(4962103 \text { bp) }\end{array}$ & 307 & 200001-200936 & 936 \\
\hline $\begin{array}{l}\text { Shewanella woodyi } \\
\text { ATCC } 51908\end{array}$ & $\begin{array}{c}\text { NC_010506 } \\
(5935403 \mathrm{bp})\end{array}$ & 327 & 200001-201005 & 1005 \\
\hline $\begin{array}{l}\text { Shimwellia blattae } \\
\text { ATCC } 29907\end{array}$ & EBLc (4158725 bp) & 376 & 200001-201029 & 1029 \\
\hline $\begin{array}{l}\text { Singulisphaera acidiphila } \\
\text { ATCC } 1392\end{array}$ & $\begin{array}{c}\text { Sinac_Contig49.1 } \\
(9629675 \mathrm{bp})\end{array}$ & 337 & 200001-201014 & 1014 \\
\hline Sorangium cellulosum Soce56 & $\begin{array}{c}\text { NC_010162 } \\
(13033779 \mathrm{bp})\end{array}$ & 329 & 200001-201029 & 1029 \\
\hline $\begin{array}{l}\text { Sphingopyxis alaskensis } \\
\text { DSM } 13593\end{array}$ & $\begin{array}{l}\text { NC_008048 } \\
(3345170 \text { bp) }\end{array}$ & 387 & 200001-201017 & 1016 \\
\hline $\begin{array}{l}\text { Sphaerobacter thermophilus } \\
\text { DSM } 20745\end{array}$ & $\begin{array}{l}\text { NC_013524 } \\
(1252731 \mathrm{bp})\end{array}$ & 335 & 200097-201092 & 995 \\
\hline $\begin{array}{l}\text { Sphingomonas wittichii } \\
\text { RW1 }\end{array}$ & $\begin{array}{c}\text { NC_009511 } \\
(5382261 \mathrm{bp})\end{array}$ & 354 & 200001-201026 & 1026 \\
\hline $\begin{array}{l}\text { Spirosoma linguale } \\
\text { ATCC } 33905\end{array}$ & $\begin{array}{c}\text { NC_013730 } \\
(8078757 \mathrm{bp})\end{array}$ & 339 & 200001-200906 & 906 \\
\hline $\begin{array}{l}\text { Starkeya novella } \\
\text { ATCC } 8093\end{array}$ & $\begin{array}{l}\text { NC_007604 } \\
(2695903 \text { bp) }\end{array}$ & 402 & 200001-201005 & 1005 \\
\hline Streptomyces albus J1074 & $\begin{array}{c}\text { CP004370 } \\
(6841649 \mathrm{bp})\end{array}$ & 252 & $1635309-1636256$ & 948 \\
\hline $\begin{array}{l}\text { Synechococcus elongatus } \\
\text { PCC } 7942\end{array}$ & $\begin{array}{l}\text { NC_007604 } \\
(2695903 \text { bp) }\end{array}$ & 402 & 200001-201005 & 1005 \\
\hline
\end{tabular}


TABLE 2: Continued.

\begin{tabular}{|c|c|c|c|c|}
\hline Name of organism & $\begin{array}{l}\text { Scaffold or genome } \\
\text { length (bp) with } \\
\text { accession number }\end{array}$ & $\begin{array}{l}\text { Total number of } \\
\text { ORF's predicted in } \\
\text { scaffold of } \\
\text { complete genome }\end{array}$ & $\begin{array}{l}\text { Predicted coding } \\
\text { region for nitrilase }\end{array}$ & $\begin{array}{l}\text { Number of } \\
\text { base-pairs }\end{array}$ \\
\hline $\begin{array}{l}\text { Syntrophobacter } \\
\text { fumaroxidans } \\
\text { DSM } 10017\end{array}$ & $\begin{array}{l}\text { NC_008554 } \\
(4990251 \mathrm{bp})\end{array}$ & 337 & 200001-200987 & 987 \\
\hline $\begin{array}{l}\text { Synechococcus sp. } \\
\text { ATCC } 27264\end{array}$ & $\begin{array}{l}\text { NC_010475 } \\
(3008047 \mathrm{bp})\end{array}$ & 431 & 200001-201008 & 1008 \\
\hline $\begin{array}{l}\text { Synechococcus elongatus } \\
\text { PCC } 6301\end{array}$ & $\begin{array}{l}\text { NC_006576 } \\
(2696255 \mathrm{bp})\end{array}$ & 402 & 200001-201005 & 1005 \\
\hline $\begin{array}{l}\text { Synechococcus sp. } \\
\text { PCC } 7002\end{array}$ & $\begin{array}{l}\text { NC_010475 } \\
(3008047 \mathrm{bp})\end{array}$ & 431 & 200001-201008 & 1008 \\
\hline $\begin{array}{l}\text { Synechococcus sp. } \\
\text { WH8102 }\end{array}$ & $\begin{array}{l}\text { NC_005070 } \\
(2434428 \text { bp) }\end{array}$ & 537 & 200001-201017 & 1017 \\
\hline Synechocystis sp. & $\begin{array}{c}\text { CP003265 } \\
(3569561 \mathrm{bp})\end{array}$ & 371 & 200001-201026 & 1026 \\
\hline $\begin{array}{l}\text { Synechocystis sp. } \\
\text { PCC } 6803\end{array}$ & $\begin{array}{l}\text { NC_017052 } \\
(3570103 \mathrm{bp})\end{array}$ & 374 & 200001-201026 & 1026 \\
\hline $\begin{array}{l}\text { Terriglobus roseus } \\
\text { KBS } 63\end{array}$ & $\begin{array}{c}\text { Terro_Contig51.1 } \\
(5227858 \mathrm{bp})\end{array}$ & 354 & 200001-200873 & 873 \\
\hline $\begin{array}{l}\text { Tistrella mobilis } \\
\text { KA081020-065 }\end{array}$ & $\begin{array}{l}\text { CP003239 } \\
\text { (1126962 bp) }\end{array}$ & 379 & 200001-201077 & 1077 \\
\hline $\begin{array}{l}\text { Variovorax paradoxus } \\
\text { (strain EPS) }\end{array}$ & $\begin{array}{c}\text { NC_014931 } \\
(6550056 \mathrm{bp})\end{array}$ & 360 & 200001-201035 & 1035 \\
\hline $\begin{array}{l}\text { Variovorax paradoxus } \\
\text { S110 }\end{array}$ & $\begin{array}{l}\text { NC_012791 } \\
(5626353 \text { bp) }\end{array}$ & 420 & 200001-201053 & 1053 \\
\hline $\begin{array}{l}\text { Verminephrobacter eiseniae } \\
\text { EF01-2 }\end{array}$ & $\begin{array}{l}\text { NC_008786 } \\
(5566749 b p)\end{array}$ & 337 & 200001-200987 & 1020 \\
\hline $\begin{array}{l}\text { Zobellia galactanivorans } \\
\text { DSM } 12802\end{array}$ & $\begin{array}{l}\text { FG20DRAFT } \\
\text { (5340688 bp) }\end{array}$ & 331 & 200001-200951 & 951 \\
\hline $\begin{array}{l}\text { Zymomonas mobilis subsp. } \\
\text { Mobilis } \\
\text { ATCC } 10988\end{array}$ & $\begin{array}{c}\text { NZ_ACQU01000006 } \\
\text { (113352 bp) }\end{array}$ & 113 & $82520-83509$ & 990 \\
\hline
\end{tabular}

TABLE 3: Manually designed motifs (MDMs) for aliphatic and aromatic nitrilases showing the presence of essential catalytic triad (E, K, and C).

\begin{tabular}{ll}
\hline Nitrilases & Manually designed motif \\
\hline \multirow{3}{*}{ Aliphatic } & {$[$ FL]-[ILV]-[AV]-F-P-E-[VT]-[FW]-[IL]-P-[GY]-Y-P-[WY] } \\
& R-R-K-[LI]-[KRI]-[PA]-T-[HY]-[VAH]-E-R \\
& C-W-E-H-[FLX]-[NQ]-[PT]-L \\
& {$[$ VA]-A-X-[AV]-Q-[AI]-X-P-[VA]-X-[LF]-[SD] } \\
Aromatic & {$[$ ALV]-[LV]-[FLM]-P-E-[AS]-[FLV]-[LV]-[AGP]-[AG]-Y-P } \\
& {$[$ AGN]-[KR]-H-R-K-L-[MK]-P-T-[AGN]-X-E-R } \\
& C-W-E-N-[HY]-M-P-[LM]-[AL]-R-X-X-[ML]-Y \\
& A-X-E-G-R-C-[FW]-V-[LIV] \\
\hline
\end{tabular}




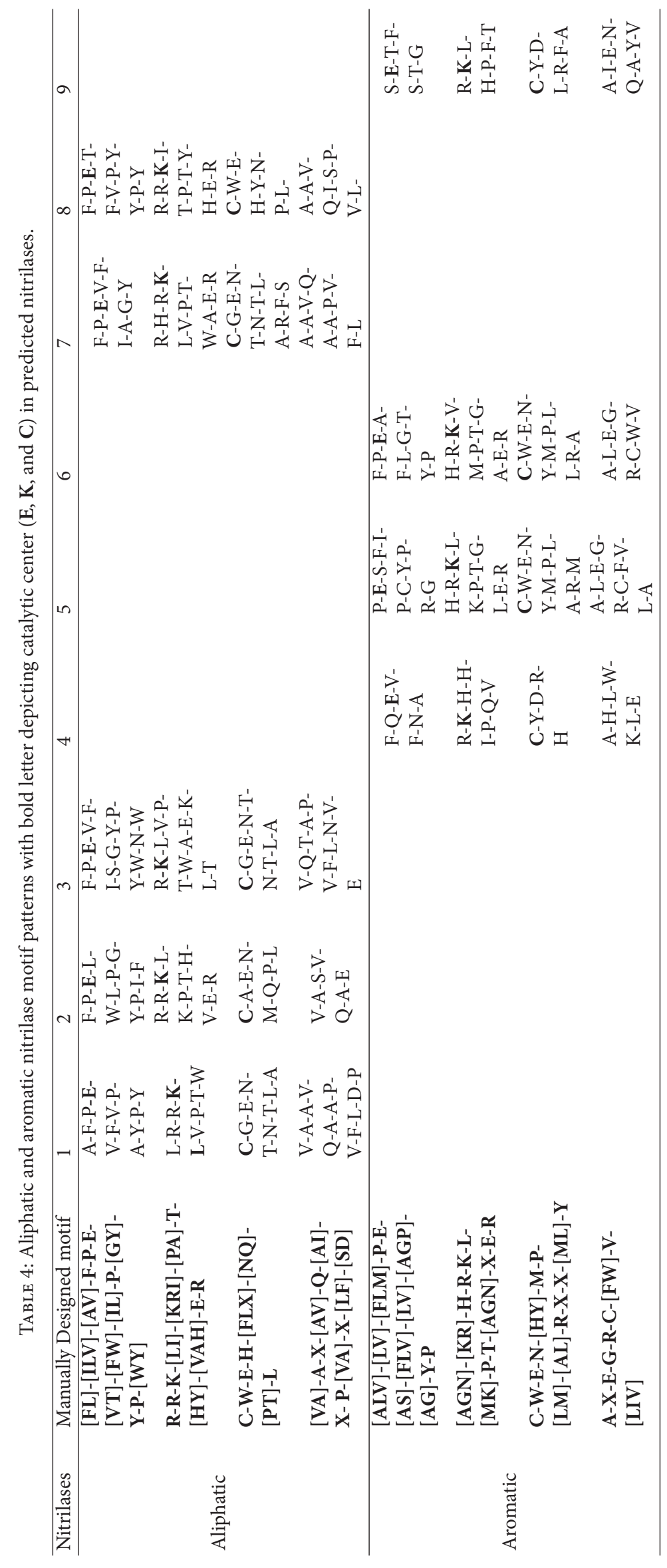


TABLE 5: Comparison of physiochemical properties of aliphatic, aromatic, and predicted nitrilase from the average consensus values reported by Sharma and Bhalla [16].

\begin{tabular}{|c|c|c|c|c|c|c|c|c|c|c|c|}
\hline Parameters & $\begin{array}{c}\text { Average value } \\
\text { for aliphatic }\end{array}$ & $\begin{array}{c}\text { Average value } \\
\text { for aromatic }\end{array}$ & 1 & 2 & 3 & 4 & 5 & 6 & 7 & 8 & 9 \\
\hline $\begin{array}{l}\text { Number of } \\
\text { amino acids }\end{array}$ & 352.2 & 309.8 & 338.0 & 331.0 & 326.0 & 260.0 & 280.0 & 310.0 & 315.0 & 342.0 & 319.0 \\
\hline $\begin{array}{l}\text { Molecular } \\
\text { weight }(\mathrm{Da})\end{array}$ & 38274.0 & 33693.5 & 36154.9 & 36491.2 & 36364.7 & 27903.3 & 31464.1 & 34938.1 & 33821.5 & 37472.7 & 34678.7 \\
\hline $\begin{array}{l}\text { Theoretical } \\
\text { pI }\end{array}$ & 5.5 & 5.5 & 5.0 & 4.9 & 6.2 & 5.2 & 5.6 & 5.4 & 4.8 & 5.4 & 5.8 \\
\hline $\mathrm{NCR}^{*}$ & 41.7 & 35.8 & 41.0 & 44.0 & 40.0 & 32.0 & 36.0 & 43.0 & 43.0 & 41.0 & 39.0 \\
\hline $\mathrm{PCR}^{*}$ & 30.3 & 29.2 & 26.0 & 25.0 & 37.0 & 21.0 & 27.0 & 34.0 & 29.0 & 30.0 & 32.0 \\
\hline $\begin{array}{l}\text { Extinction } \\
\text { coefficients } \\
\left(\mathrm{M}^{-1} \mathrm{~cm}^{-1}\right) \text { at } \\
280 \mathrm{~nm} \\
\end{array}$ & 50213.3 & 43975.0 & 45295.0 & 33015.0 & 43890.0 & 35200.0 & 62465.0 & 53400.0 & 47900.0 & 38305.0 & 31775.0 \\
\hline Instability index & 41.2 & 38.5 & 30.1 & 52.5 & 27.0 & 27.7 & 28.6 & 39.6 & 46.6 & 36.6 & 38.5 \\
\hline Aliphatic index & 89.40 & 89.90 & 94.1 & 87.9 & 93.6 & 81.1 & 76.0 & 90.9 & 86.2 & 92.8 & 89.3 \\
\hline $\begin{array}{l}\text { Grand average } \\
\text { of } \\
\text { hydropathicity } \\
\text { (GRAVY) }\end{array}$ & 00.10 & 00.01 & 0.027 & -0.17 & -0.14 & -0.051 & -0.283 & -0.109 & 0.045 & -0.052 & -0.002 \\
\hline
\end{tabular}

$\mathrm{NCR}^{*}$ : negatively charged residues; $\mathrm{PCR}^{*}$ : positively charged residues.

designed motifs (MDMs) also differentiated the in silico predicted nitrilases as aliphatic or aromatic [12] as the designed motifs are class specific. All the four motifs identified were uniformly conserved throughout the two sets of aliphatic and aromatic nitrilases as mentioned in Table 4.

The sequences belonged to the nitrilase superfamily, showing the presence of the catalytic triad Glu (E), Lys $(\mathrm{K})$, and Cys (C) to be conserved throughout. Phylogenetic analysis using the MEGA 6.0 version for the aliphatic and aromatic set of protein sequences revealed two major clusters. Neighbor Joining (NJ) tree used for phylogenetic analysis revealed that in silico predicted proteins (this study) and previously identified nitrilases as aliphatic and aromatic [16] were found to be grouped in their respective clusters (Figure 1).

Aliphaticity and aromaticity of in silico predicted and characterized nitrilases were differentiated based on their physiochemical properties. The physicochemical properties of the predicted set of nitrilase were deduced using the ProtParam subroutine of Expert Protein Analysis System (ExPASy) from the proteomic server of the Swiss Institute of Bioinformatics (SIB), in order to predict aromaticity or aliphaticity. Several of the parameters (number of amino acids, molecular weight, number of negatively charged residues, extinction coefficients, and grand average of hydropathicity) listed in Table 5 are closer to the consensus values reported for aromatic and aliphatic nitrilases, supporting that the predicted set of nitrilase has aromatic or aliphatic substrate specificity (Table 5).
In silico predictions were verified by in vitro validation of the predicted proteins. Common nitriles (aliphatic, aromatic, and aryl nitriles) and potassium cyanide ( $\mathrm{KCN})$ were tested to check for the nitrile/cyanide transforming ability of the predicted proteins. Out of nine predicted proteins eight were found active for different nitriles, whereas Flavobacterium indicum was found to hydrolyze toxic cyanide (KCN) into nontoxic form (Table 6). The present approach contributed to finding novel sources of desired nitrilase from microbial genome database.

\section{Conclusion}

Genome mining for novel sources of nitrilases has predicted 138 sources for nitrilases. In vitro validation of the selected nine predicted sources of nitrilases for nitrile/cyanide hydrolyzing activity has furthered the scope of genome mining approaches for the discovery of novel sources of enzymes.

\section{Conflicts of Interest}

The authors declare that they have no conflicts of interest.

\section{Acknowledgments}

The authors are thankful to the Department of Biotechnology (DBT), New Delhi, for the continuous support to the Bioinformatics Centre, Himachal Pradesh University, Summer Hill, Shimla, India. 


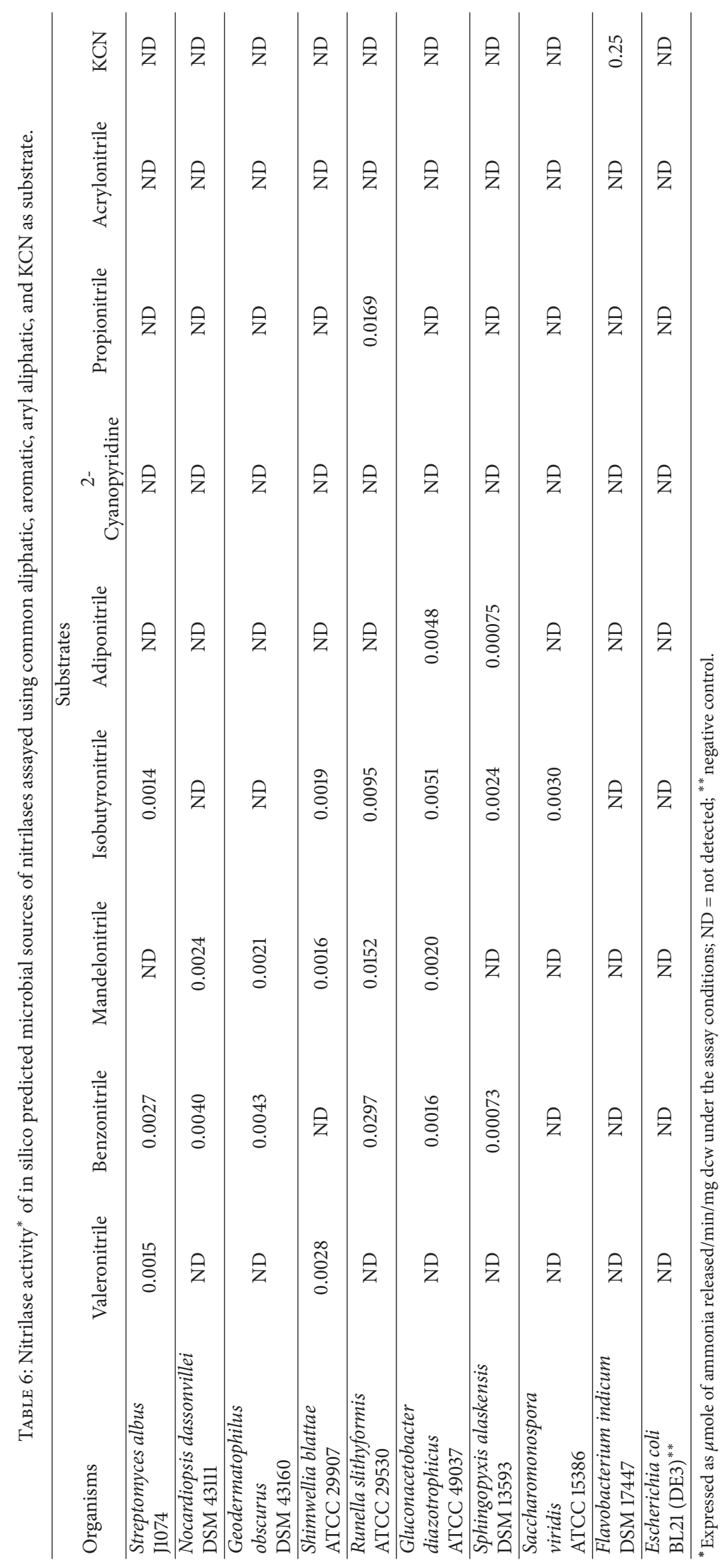




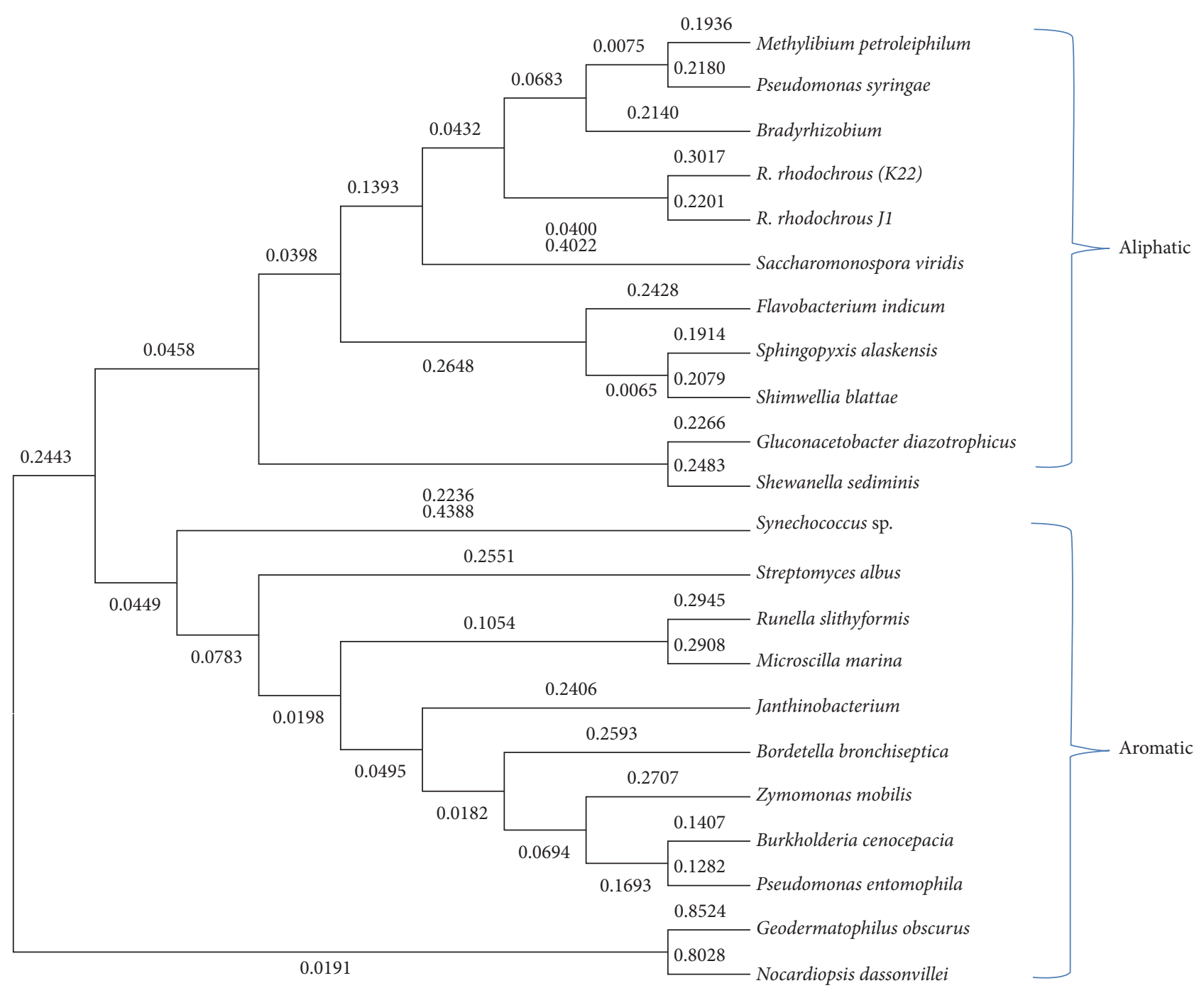

FIGURE 1: Neighbor Joining (NJ) method differentiating characterized and in silico predicted as aliphatic and aromatic nitrilases.

\section{References}

[1] J. L. Seffernick, S. K. Samanta, T. M. Louie, L. P. Wackett, and M. Subramanian, "Investigative mining of sequence data for novel enzymes: a case study with nitrilases," Journal of Biotechnology, vol. 143, no. 1, pp. 17-26, 2009.

[2] M. Land, L. Hauser, S. Jun et al., "Insights from 20 years of bacterial genome sequencing," Functional \& Integrative Genomics, vol. 15, no. 2, pp. 141-161, 2015.

[3] D. Yadav, "Relevance of bioinformatics in the era of omics driven research," Journal of Next Generation Sequencing \& Applications, vol. 2, no. 1, article e102, 2015.

[4] Y. Feng, Y. Zhang, C. Ying, D. Wang, and C. Du, "Nanoporebased fourth-generation DNA sequencing technology," Genomics, Proteomics \& Bioinformatics, vol. 13, no. 1, pp. 4-16, 2015.

[5] S. G. Van Lanen and B. Shen, "Microbial genomics for the improvement of natural product discovery," Current Opinion in Microbiology, vol. 9, no. 3, pp. 252-260, 2006.

[6] X. J. Luo, H. L. Yu, and J. H. Xu, "Genomic data mining: an efficient way to find new and better enzymes," Enzyme Engineering, vol. 1, article 104, 2012.
[7] P. De Sousa-Pereira, F. Amado, J. Abrantes, R. Ferreira, P. J. Esteves, and R. Vitorino, "An evolutionary perspective of mammal salivary peptide families: cystatins, histatins, statherin and PRPs," Archives of Oral Biology, vol. 58, no. 5, pp. 451-458, 2013.

[8] J. L. Adrio and A. L. Demain, "Microbial enzymes: tools for biotechnological processes," Biomolecules, vol. 4, no. 1, pp. 117-139, 2014.

[9] J. Raj, N. Singh, S. Prasad, A. Seth, and T. C. Bhalla, "Bioconversion of benzonitrile to benzoic acid using free and agar entrapped cells of Nocardia globerula NHB-2," Acta Microbiologica et Immunologica Hungarica, vol. 54, no. 1, pp. 79-88, 2007.

[10] M. A. Rao, R. Scelza, R. Scotti, and L. Gianfreda, "Role of enzymes in the remediation of polluted environments," Journal of Soil Science and Plant Nutrition, vol. 10, no. 3, pp. 333-353, 2010.

[11] P. Kaul and Y. Asano, "Strategies for discovery and improvement of enzyme function: state of the art and opportunities," Microbial Biotechnology, vol. 5, no. 1, pp. 18-33, 2012.

[12] N. N. Sharma, M. Sharma, and T. C. Bhalla, "Nocardia globerula NHB-2 nitrilase catalysed biotransformation of 4-cyanopyridine to isonicotinic acid," AMB Express, vol. 2, article 25, 2012. 
[13] S. K. Bhatia, P. K. Mehta, R. K. Bhatia, and T. C. Bhalla, "Optimization of arylacetonitrilase production from Alcaligenes sp. MTCC 10675 and its application in mandelic acid synthesis," Applied Microbiology and Biotechnology, vol. 98, no. 1, pp. 8394, 2014.

[14] J.-S. Gong, Z.-M. Lu, H. Li, J.-S. Shi, Z.-M. Zhou, and Z.-H. $\mathrm{Xu}$, "Nitrilases in nitrile biocatalysis: recent progress and forthcoming research," Microbial Cell Factories, vol. 11, article 142, 2012.

[15] P. W. Ramteke, N. G. Maurice, B. Joseph, and B. J. Wadher, "Nitrile-converting enzymes: an eco-friendly tool for industrial biocatalysis," Biotechnology and Applied Biochemistry, vol. 60, no. 5, pp. 459-481, 2013.

[16] N. Sharma and T. C. Bhalla, "Motif design for nitrilases," Journal of Data Mining in Genomics \& Proteomics, vol. 3, article 119, 2012.

[17] N. Sharma, R. Kushwaha, J. S. Sodhi, and T. C. Bhalla, "In silico analysis of amino acid sequences in relation to specificity and physiochemical properties of some microbial nitrilases," Journal of Proteomics and Bioinformatics, vol. 2, no. 4, pp. 185-192, 2009.

[18] T. C. Bhalla, A. Miura, A. Wakamoto, Y. Ohba, and K. Furuhashi, "Asymmetric hydrolysis of $\alpha$-aminonitriles to optically active amino acids by a nitrilase of Rhodococcus rhodochrous PA-34," Applied Microbiology and Biotechnology, vol. 37, no. 2, pp. 184-190, 1992.

[19] V. Vejvoda, D. Kubáč, A. Davidová et al., "Purification and characterization of nitrilase from Fusarium solani IMI196840," Process Biochemistry, vol. 45, no. 7, pp. 1115-1120, 2010.

[20] G. V. Dennett and J. M. Blamey, "A new thermophilic nitrilase from an antarctic hyperthermophilic microorganism," Frontiers in Bioengineering and Biotechnology, vol. 4, article 5, 2016.

[21] J. K. Fawcett and J. E. Scott, "A rapid and precise method for the determination of urea," Journal of Clinical Pathology, vol. 13, pp. 156-159, 1960.

[22] I. Friedberg, "Automated protein function prediction-the genomic challenge," Briefings in Bioinformatics, vol. 7, no. 3, pp. 225-242, 2006.

[23] J. Armengaud, "A perfect genome annotation is within reach with the proteomics and genomics alliance," Current Opinion in Microbiology, vol. 12, no. 3, pp. 292-300, 2009.

[24] M. S. Poptsova and J. P. Gogarten, "Using comparative genome analysis to identify problems in annotated microbial genomes," Microbiology, vol. 156, no. 7, pp. 1909-1917, 2010. 

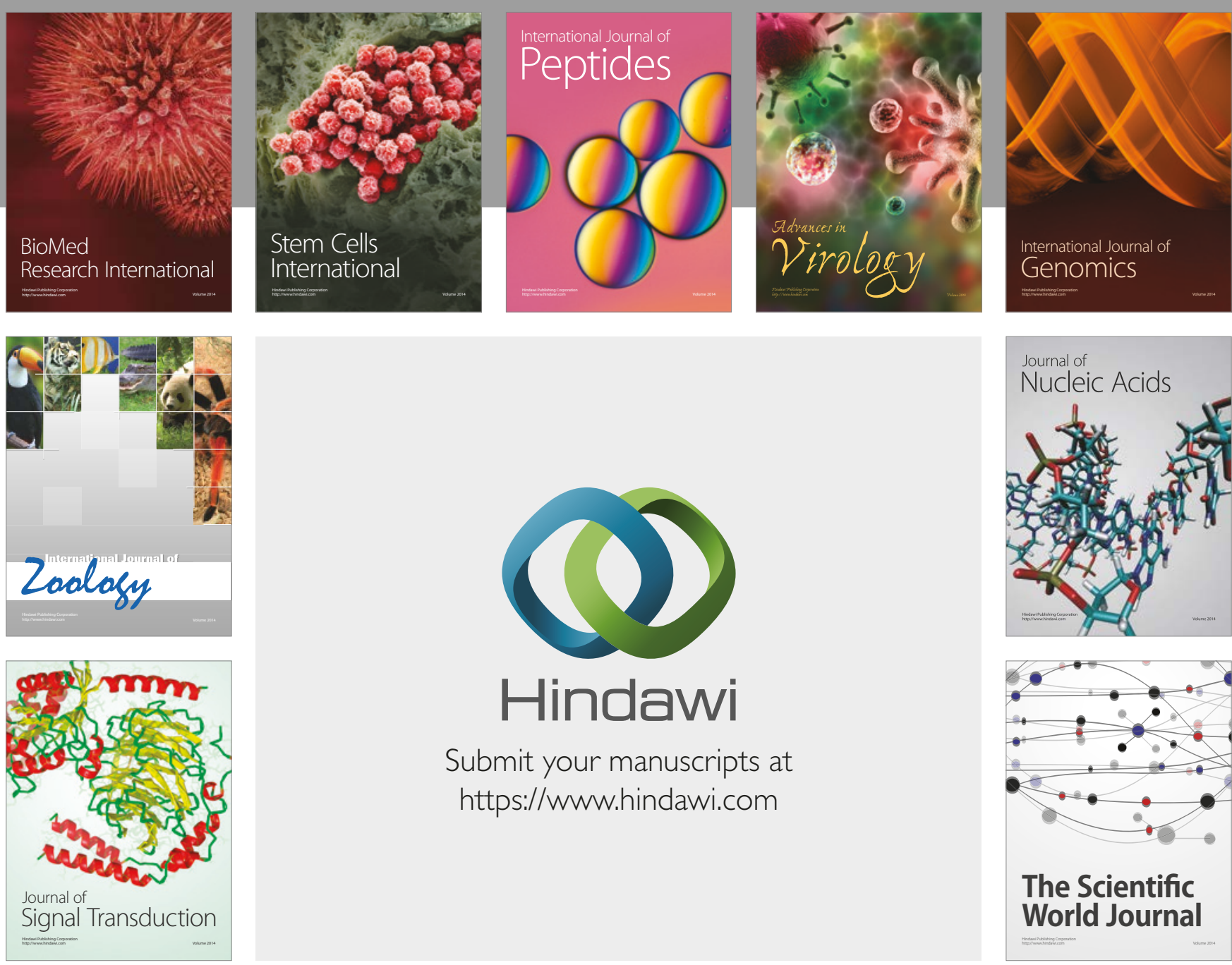

Submit your manuscripts at

https://www.hindawi.com
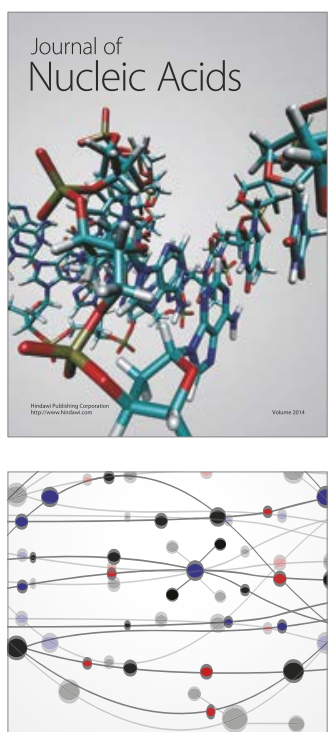

The Scientific World Journal

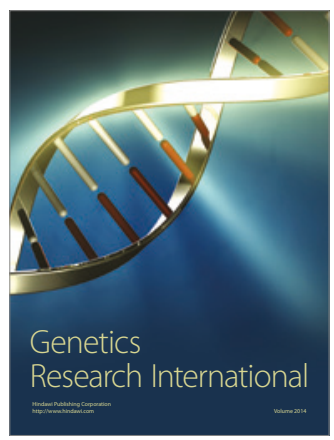

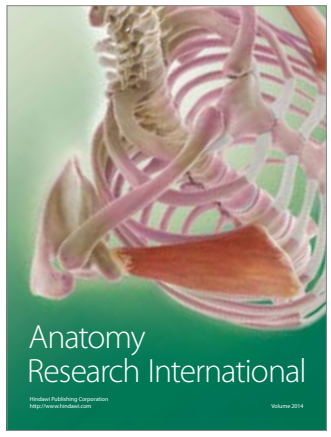

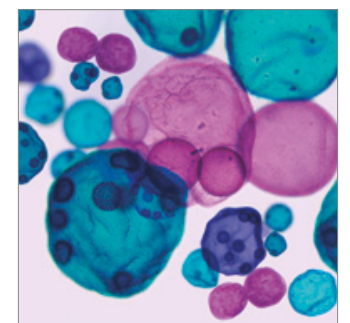

International Journal of Microbiology
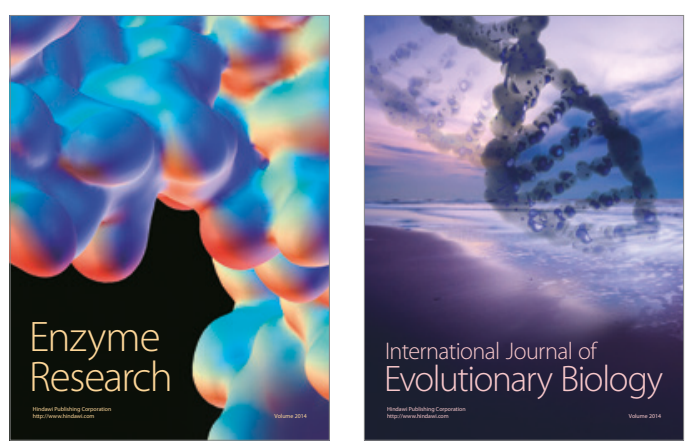
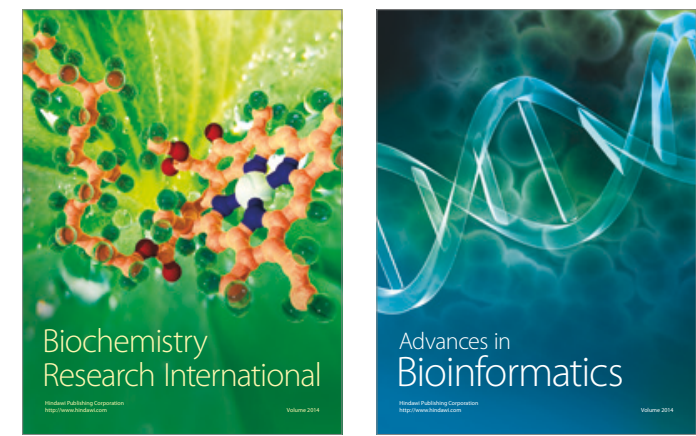

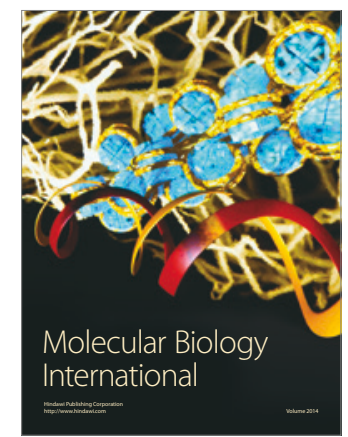

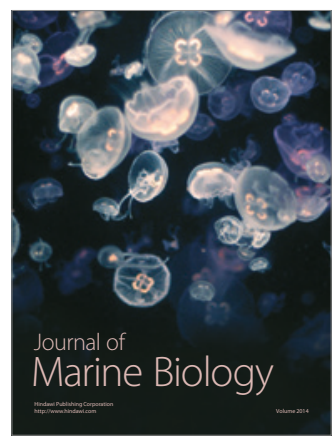

